\title{
Role of Exercise as a Modulating Factor in Arrhythmogenic Cardiomyopathy
}

\author{
Alessandro Zorzi ${ }^{1} \cdot$ Alberto Cipriani $^{1} \cdot$ Riccardo Bariani $^{1} \cdot$ Kalliopi Pilichou $^{1} \cdot$ Domenico Corrado $^{1} \cdot$ Barbara Bauce $^{1}$
}

Accepted: 9 March 2021 / Published online: 7 May 2021

(C) The Author(s) 2021

\begin{abstract}
Purpose of Review The review addresses the role of exercise in triggering ventricular arrhythmias and promoting disease progression in arrhythmogenic cardiomyopathy (AC) patients and gene-mutation carriers, the differential diagnosis between $\mathrm{AC}$ and athlete's heart and current recommendations on exercise activity in AC.

Recent Findings AC is an inherited heart muscle disease caused by genetically defective cell-to-cell adhesion structures (mainly desmosomes). The pathophysiological hallmark of the disease is progressive myocyte loss and replacement by fibro-fatty tissue, which creates the substrates for ventricular arrhythmias. Animal and human studies demonstrated that intense exercise, but not moderate physical activity, may increase disease penetrance, worsen the phenotype, and favor life-threatening ventricular arrhythmias. It has been proposed that in some individuals prolonged endurance sports activity may in itself cause AC (so-called exercise-induced AC).

Summary The studies agree that intense physical activity should be avoided in patients with AC and healthy gene-mutation carriers. However, low-to-moderate intensity exercise does not appear detrimental and these patients should not be entirely deprived from the many health benefits of physical activity.
\end{abstract}

Keywords Athlete's heart $\cdot$ Exercise prescription $\cdot$ Sports cardiology $\cdot$ Sudden death $\cdot$ Ventricular arrhythmias

\section{Introduction}

Arrhythmogenic cardiomyopathy (ACM) is an inherited heart muscle disease caused by genetically defective cell-to-cell

This article is part of the Topical Collection on Myocardial Disease

Barbara Bauce

barbara.bauce@unipd.it

Alessandro Zorzi

alessandro.zorzi@unipd.it

Alberto Cipriani

alberto.cipriani@unipd.it

Riccardo Bariani

riccardo.bariani@unipd.it

Kalliopi Pilichou

kalliopi.pilichou@unipd.it

Domenico Corrado

domenico.corrado@unipd.it

1 Department of Cardiac, Thoracic, and Vascular Sciences and Public Health, University of Padova, Via Giustiniani, 2, 35128 Padova, Italy adhesion structures (mainly desmosomes) [1]. The pathophysiological mechanism of ACM is a progressive myocyte loss and substitution by fibro-fatty scar, which represents the substrate for re-entrant ventricular tachycardia (VT) and myocardial dysfunction [2]. Although wall motion abnormalities resulting from myocardial scarring are usually more evident in the thinner right ventricle (RV), cardiac magnetic resonance (CMR) studies demonstrated that ACM is often biventricular $[3,4 \bullet]$. However, only in a minority of patients the degree of myocyte loss is severe enough to cause symptomatic ventricular dysfunction. Life-threatening ventricular arrhythmias (VAs), usually ventricular fibrillation (VF), and heart failure may also occur abruptly, during the so-called hot-phases, characterized by acute bouts of myocyte necrosis and inflammation similarly to acute myocarditis [5].

Sports activity is a well-known arrhythmic trigger and ACM is a leading cause of sudden death (SD) in the athlete [6-10]. More recently, intense exercise has been recognized as a modulating factor promoting phenotypic penetrance and disease progression both in animal studies and in familial ACM [11-15, 16••, 17-23]. Observation that some longterm endurance athletes may develop disease features or even 
overt ACM in the absence of gene mutations has led to the hypothesis that ACM may be entirely "exercise-induced" [24]. On the other hand, there is no demonstration that even low-to-moderate intensity exercise may be detrimental in patients with ACM or in their gene-positive family members and recent recommendations suggest not to deprive entirely these subjects from the many benefits of physical activity [25].

In the present article, we will review the role of exercise in triggering ventricular arrhythmias and promoting disease progression. We will also briefly address the differential diagnosis between ACM and athlete's heart. Finally, we will discuss current recommendations about competitive sports and leisure time exercise in ACM patients.

\section{Animal Studies}

The role of physical exercise as a trigger of arrhythmic events or disease progression factor has been evaluated in different animal models.

In 2006, Kirchhof and coworkers investigated the effects of age and endurance training on heterozygous plakoglobindeficient $(J U P+/-)$ mice [11]. They found that RV dilatation and dysfunction as well as VAs were exacerbated by daily swimming, supporting that endurance training could accelerate disease progression. However, neither cardiomyocyte abnormalities or fibrofatty replacement nor ultrastructural changes of desmosomes or adherens junctions were observed in trained mice. Further studies from the same group demonstrated that a load-reducing therapy (furosemide and nitrates) prevents training-induced disease development and progression as well as VAs in $J U P$-deficient (+/-) mice; however, these results have yet to be confirmed in the clinical setting [12].

The effect of endurance training was also assessed in a mouse model overexpressing a nonsense plakophilin-2 (PKP2) gene mutation [13]. Endurance training was associated with abnormal localization and distribution of the $\mathrm{Cx} 43$ and exacerbated by 5 -fold the risk of developing RV dysfunction. In another study, endurance training was evaluated related to the gradient overexpression of the transgene carrying another nonsense PKP2 gene-mutation [14]. In this case, exercise was associated with RV outflow tract dilatation but no electrocardiographic changes or higher inducibility of VAs. Noteworthy, also transgenic PKP2 animals, similarly to the $J U P$-deficient mice, showed no histological/ultrastructural changes typical of ACM regardless training. Both these models suggest that exercise may induce ventricular dilation/ dysfunction and favor VAs in mice with abnormal desmosomal proteins but do not cause the structural and ultrastructural changes typical of ACM, suggesting that the deleterious effects of exercise are potentially reversible.
In contrast, a recent study on a conditional heterozygous desmoplakin $(D S P)$ mouse model showed that treadmill exercise partially rescued ACM phenotype by normalizing twothirds of the aberrant regulated genes in sedentary haploinsufficient $D S P$ mice, particularly those related to inflammation, epithelial-mesenchymal transition, and oxidative phosphorylation [15]. According to this model, treadmill exercise did not worsen cardiac systolic function or electrophysiologic parameters but was associated with eccentric cardiac hypertrophy and significant reduction of the apoptotic index in the presence of normally distributed intercalated discs proteins.

\section{ACM as a Cause of Exercise-Related Sudden Death}

The recognition of ACM as a cause of exercise-related SD dates back to 1988 . Thiene et al. found that 12 of $60(20 \%)$ young $(<35$ year-old) victims of SD in the Veneto region of Italy had morphologic features of RV cardiomyopathy. Ten of the subjects had died during exertion [6]. Further studies on larger populations confirmed that ACM is one of the leading causes of SD in athletes of the Veneto region of Italy (14\% of cases) and that athletes with ACM had 5.4 times higher risk of dying suddenly than their sedentary counterpart [7]. In a British study on SD in athletes, whose hearts were referred for post-mortem to a tertiary center, the prevalence of ACM was similar (13\%) to that found in the Italian series [9]. Conversely, ACM accounted for only $6 \%$ of SD cases in the USA [26]. Such discrepancy may depend on one hand on the experience of the pathologist or coroner performing postmortem analysis, who may miss this rare and peculiar disease, and on the fact that the US series included many black athletes who are rarely affected by ACM.

Systematic preparticipation screening has demonstrated to reduce the risk of SD from classic ACM variants (rightdominant or biventricular) because of its ability to identify early asymptomatic patients by investigating abnormal electrocardiogram (ECG) findings or VAs at exercise testing [8]. However, a subset of patients exhibits an ACM variant that predominantly affects the left ventricle (left-dominant). ECG abnormalities such as $\mathrm{T}$-wave inversion in the lateral leads V4-V6 and low QRS voltages in the limb leads and left ventricular regional systolic function abnormalities may be observed, but standard clinical investigations are often normal and the diagnosis requires demonstration of subepicardial/ midmyocardial late enhancement on cardiac magnetic resonance (Fig. 1) [28]. For this reason, the incidence of SD from classic ACM has markedly decreased since the introduction of pre-participation screening, while the difficulty to diagnose "left dominant" variant had led to the fact that this clinical entity is now an increasingly reported substrate of SD [29]. 
Fig. 1 Representative case of leftdominant arrhythmogenic cardiomyopathy variant in a patient with a desmoplakin-gene mutation. The left-dominant arrhythmogenic cardiomyopathy variant may show an unremarkable electrocardiogram except for low-QRS voltages in the limb leads (a) and normal dimension and systolic function of both ventricles (end-diastolic frame of cine cardiac magnetic resonance sequence in long-axis 4-chamber view). b Post-contrast cardiac magnetic resonance images disclose myocardial fibrosis in the form of a late gadolinium enhancement stria in the epicardium of the left ventricular lateral wall (arrowheads) and midmural layer of the interventricular septum (arrows) (c) (reproduced with permission from: De Lazzari M et al. J Am Heart Assoc. 2018 Nov 20;7(22):e009855. doi: 10.1161/JAHA.118.009855) [27]
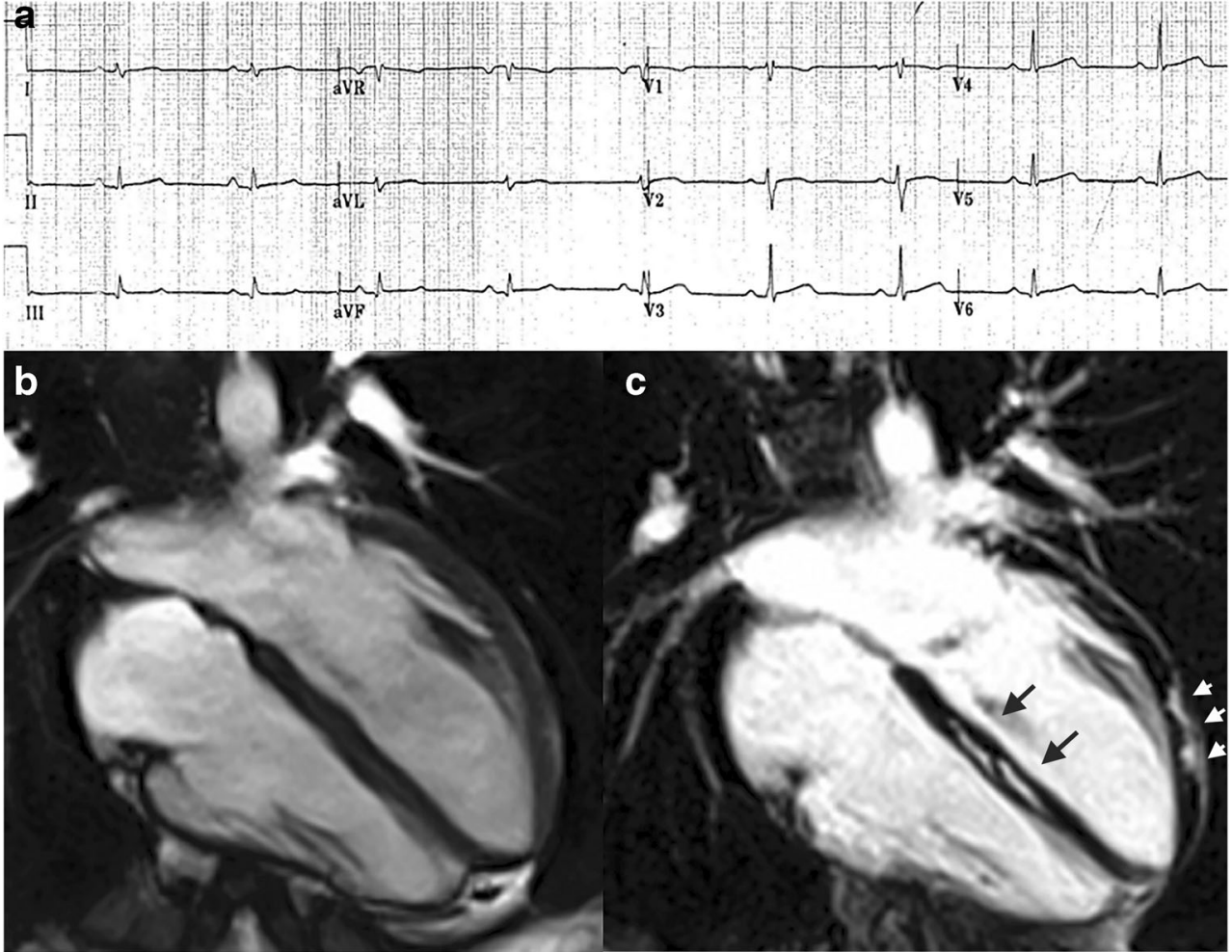

According to recent studies, exercise testing for evaluation of VAs may provide additional value for raising the suspicion of an underlying left-dominant ACM [30]. In particular, the occurrence of exercise-induced repetitive premature ventricular beats with a right-bundle-branch block and superior axis pattern (suggesting an origin from the infero-lateral left ventricular wall) may deserve more in-depth investigation by cardiac magnetic resonance [31].

\section{Role of Sports Activity in Promoting Disease Penetrance and Progression}

Table 1 summarizes the design and the results of the studies that addressed the role of exercise activity in modifying the clinical course of patients with ACM and in genotype positive/phenotype negative individuals [16••, 17-23] The studies agree that intense and prolonged physical activity: (1) favors the development of the disease in genotype positive/phenotype negative patients; (2) worsen the degree of ventricular dysfunction in patients with overt ACM; (3) increases the likelihood of sustained ventricular arrhythmias and implantable cardioverter-defibrillator (ICD) interventions (Figs. 2 and 3). Common limitations of these studies included their retrospective nature, the fact that the type and amount of exercise was self-reported and that the definition of type and amount of exercise was heterogeneous.
Many young patients with ACM may wish to participate in recreational and leisure time exercise activity, given the recognized beneficial effects of a physically active lifestyle. On the other hand, a sedentary behavior may carry adverse consequences (e.g., obesity, depression, social deprivation, increased risk of coronary artery disease) that potentially outweigh the benefits. It is difficult to infer from the majority of the studies whether there is a dose-response correlation between exercise and adverse outcome (i.e., ideally ACM patients should not exercise at all) or if there is a threshold of exercise type, intensity and/or duration that can be considered safe. However, the investigations that specifically addressed the outcome of ACM patients engaged in low-to-moderate intensity exercise found that their outcome was similar to that of sedentary patients. These findings suggest that not all exercise is the same and that patients with ACM may be able to derive the benefits of leisure time exercise without excess risk.

\section{The Theory of Exercise-Induced ACM}

So far, we have discussed the potential role of exercise in modifying the natural history of patients with ACM or of their genotype-positive/phenotype-negative relatives. It has been proposed that intense and prolonged endurance exercise may cause ACM in the absence of gene mutations, so-called exercise-induced ACM. This theory was first advanced by Heidbuchel et al. in 2003, who described a series of 46 


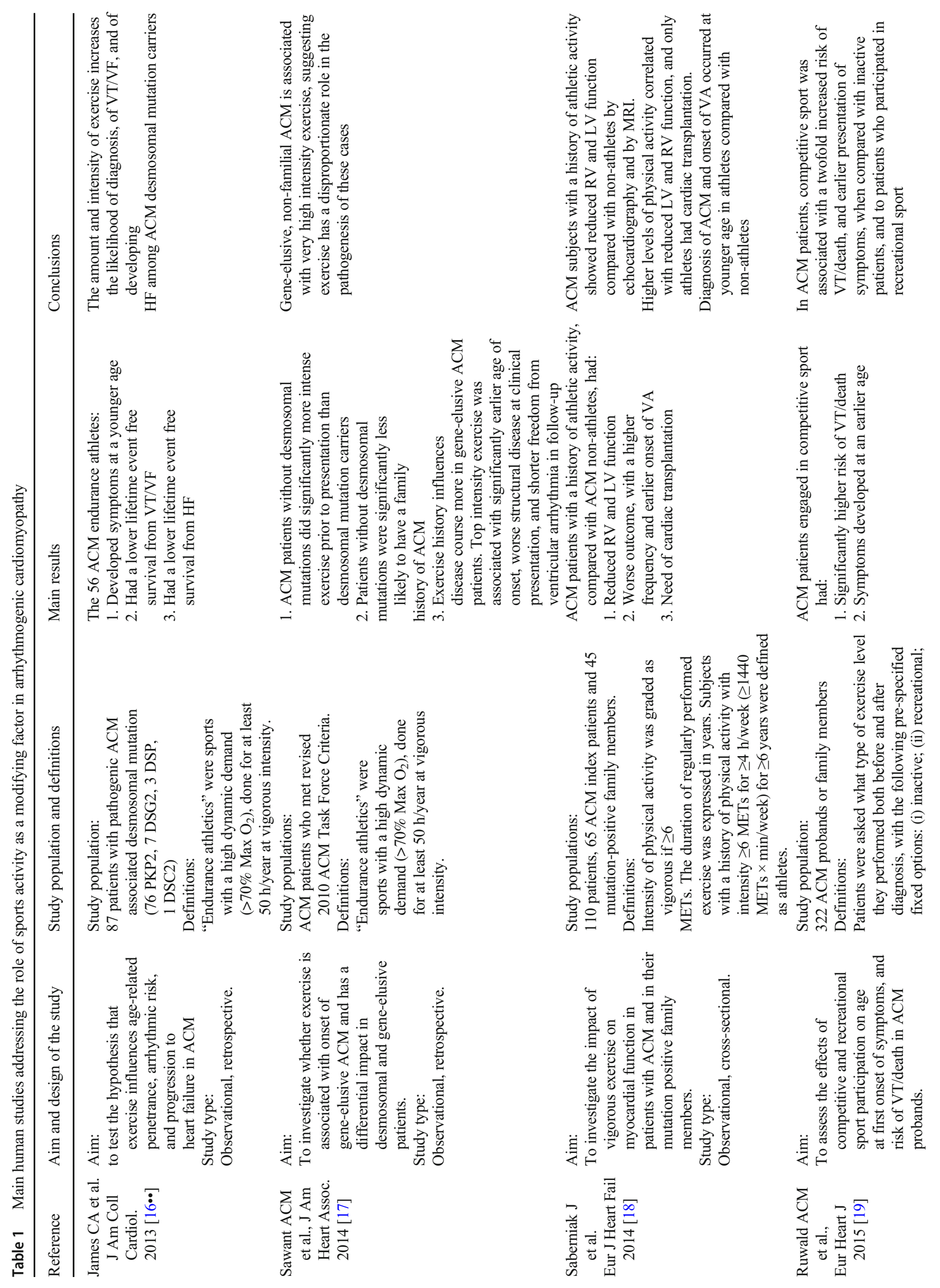



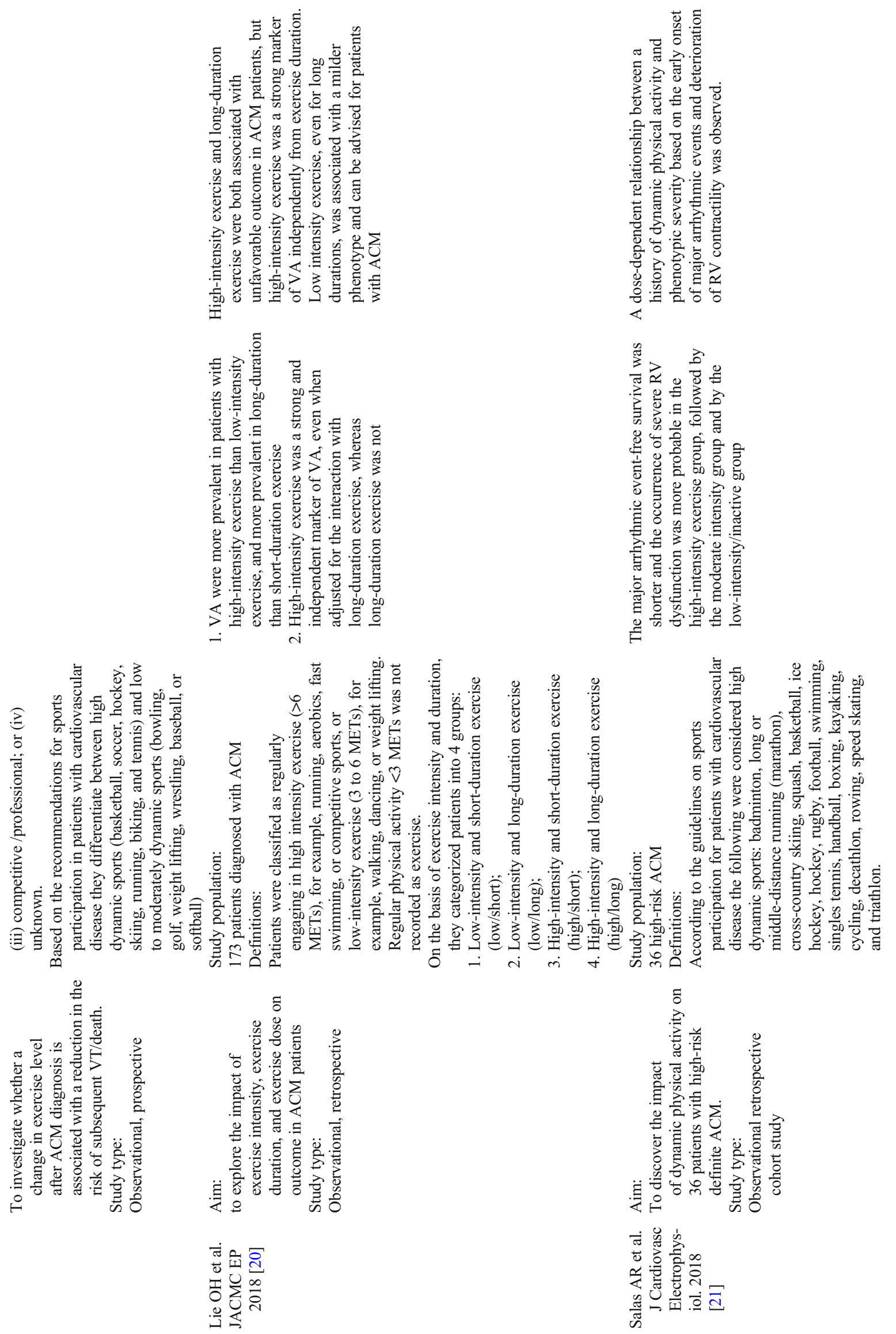


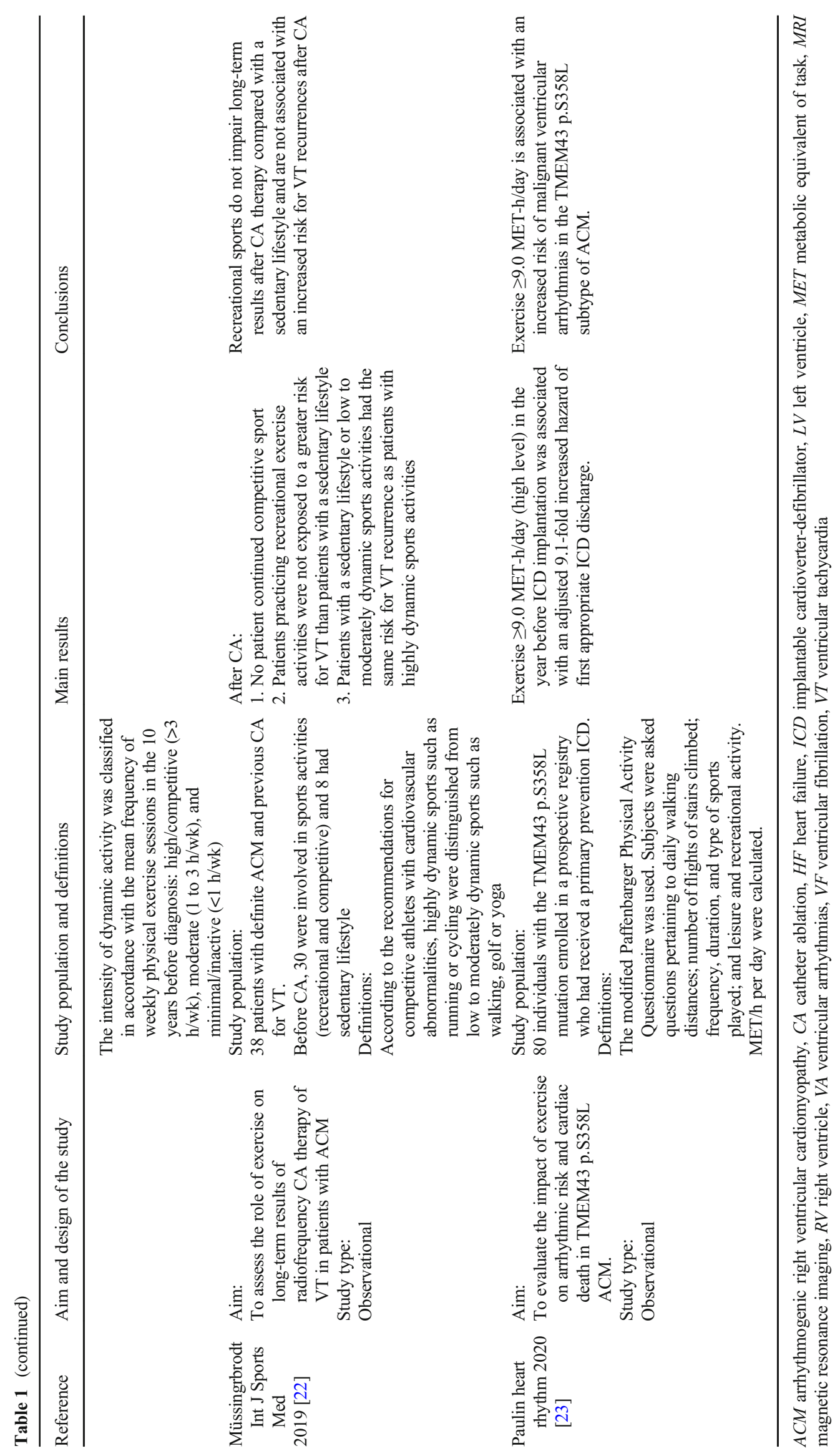




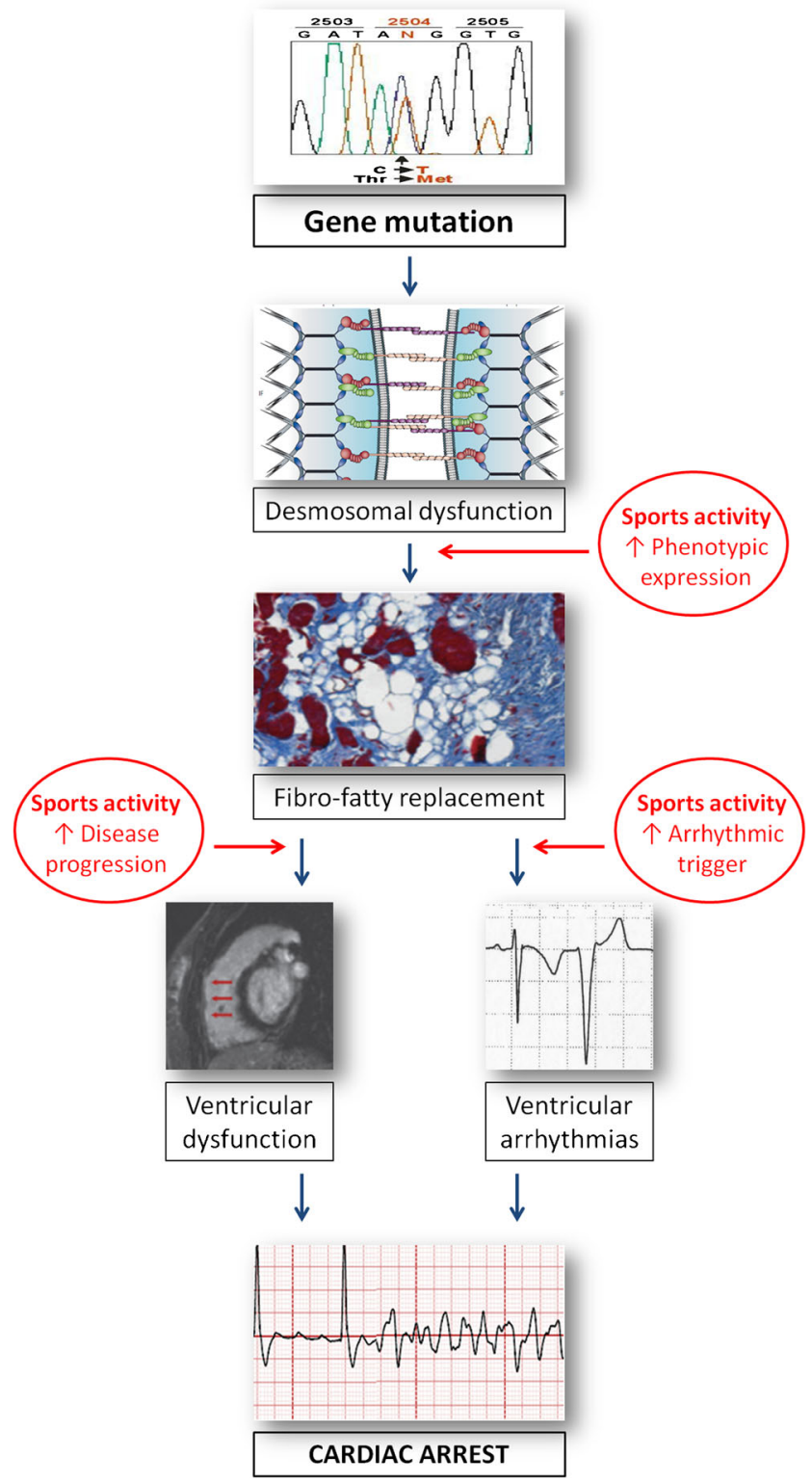

Fig. 2 Role of intense sports activity in the natural history of arrhythmogenic cardiomyopathy, from desmosomal-gene mutation to phenotypic expression and cardiac arrest due to ventricular fibrillation. Sports activity may promote development of phenotypic expression, accelerate disease progression, and trigger life-threatening ventricular arrhythmias (reproduced with permission from: Corrado D, Zorzi A. Eur Heart J 2015 Jul 14;36(27):1708-10. doi: 10.1093/eurheartj/ehv183. Epub 2015 May 12, with permission from Oxford University Press) [32]

endurance athletes (predominantly cyclists) presenting with VAs. Because of associated abnormalities on electrocardiogram, Holter monitoring, and cardiac imaging, $60 \%$ met the criteria for definite ACM and 30\% for probable ACM but only 1 athlete had a family history suggestive of ACM. During follow-up, almost $40 \%$ experienced major arrhythmic events [33]. Subsequent genotype-phenotype studies showed that ACM features in subjects who engaged in high-intensity exercise were typically not associated with a negative molecular genetics analysis for desmosomal gene mutations (so-called gene-elusive patients) ACM [17, 34]. In the "John Hopkins registry," gene-elusive patients, particularly those $<25$ yearold, reported performing significantly more intense exercise prior to their diagnosis compared to desmosomal-gene mutation carriers [17]. Another analysis of the same registry, which focused on the effect of physical activity on ICD carriers, found that exercise restriction reduced the arrhythmic risk more in gene-elusive patients than in those with desmosomal mutations [35]. These observations further support the hypothesis that ACM may be acquired through intense exercise. Others reported that athletes may exhibit arrhythmogenic ventricular abnormalities typical of ACM variants such as isolated non-ischemic left ventricular scar or a particular form of RV outflow tract tachycardia associated with epicardial scar [36-38].

Taken together, these findings suggest that even in the absence of desmosomal-gene mutations, the increased hemodynamic load induce by prolonged intense exercise may be enough to cause permanent myocardial damage in some cases. However, it has to be noted that this phenomenon is rare as many studies demonstrated a lack of long-term adverse remodelling in large series of top-level athletes [24]. For this reason, it is plausible that a combination of a genetic predisposition that remains unknown and environmental factors (including exercise) is needed for an athlete with no mutations in known ACM-causing genes to develop the disease.

\section{Sports Activity in ACM Patients with an ICD}

The risk of SD during exercise is the main reason why patients with ACM are advised against engaging in sport activities. The ICD may offer protection against SD and may theoretically allow safe sport participation of athletes with ACM. Traditionally, there has been concern that intense exercise may influence the efficacy and safety of ICD therapy and increase the risk of inappropriate shocks, damage to the device, and lead failure [39] (Fig. 4). A multinational registry that recruited 372 athletes provided reassuring data about sports participation of ICD carriers by showing no arrhythmic deaths, resuscitated cardiac arrests, or shock-related injuries during follow-up and no increased risk of technical malfunction. On the other hand, the study confirmed the detrimental effect of competitive sports on the arrhythmic outcome of ACM patients by showing that an underlying ACM was the only variable associated with exercise-induced ICD shock [40॰]. A sub-analysis on the arrhythmic outcome of ICD carriers enrolled in the European arm of the Registry who engaged in leisure time physical activity (mostly endurance disciplines such as running or cycling) showed that the risk of receiving appropriate ICD interventions was lower $(6.3 \%$ vs. $20.2 \%$ ) than their counterpart of competitive athletes. Also, in 
Fig. 3 Representative example of the role of endurance exercise in worsening the arrhythmogenic cardiomyopathy phenotype. A 38-year-old runner received a diagnosis of arrhythmogenic cardiomyopathy after investigation of ventricular arrhythmias and ECG abnormalities at preparticipation screening. Genetic testing revealed the presence of a plakophilin-2 gene mutation. At the time of diagnosis, cardiac magnetic resonance 4-chamber view on cine sequences found dilatation of the right ventricle with mild dysfunction (a) and diffuse right ventricular lateenhancement on post-contrast sequences (arrowheads) (b). Although according to the Italian law he was considered not eligible for competitive sports activity, he continued to practice highintensity endurance training. After 4 years, a new cardiac magnetic resonance showed a more enlarged right ventricle, an apical aneurysm (arrow), and a moderate right ventricular dysfunction (c). Post-contrast sequences confirmed the presence of a diffuse right ventricular late enhancement (arrowheads) (d)
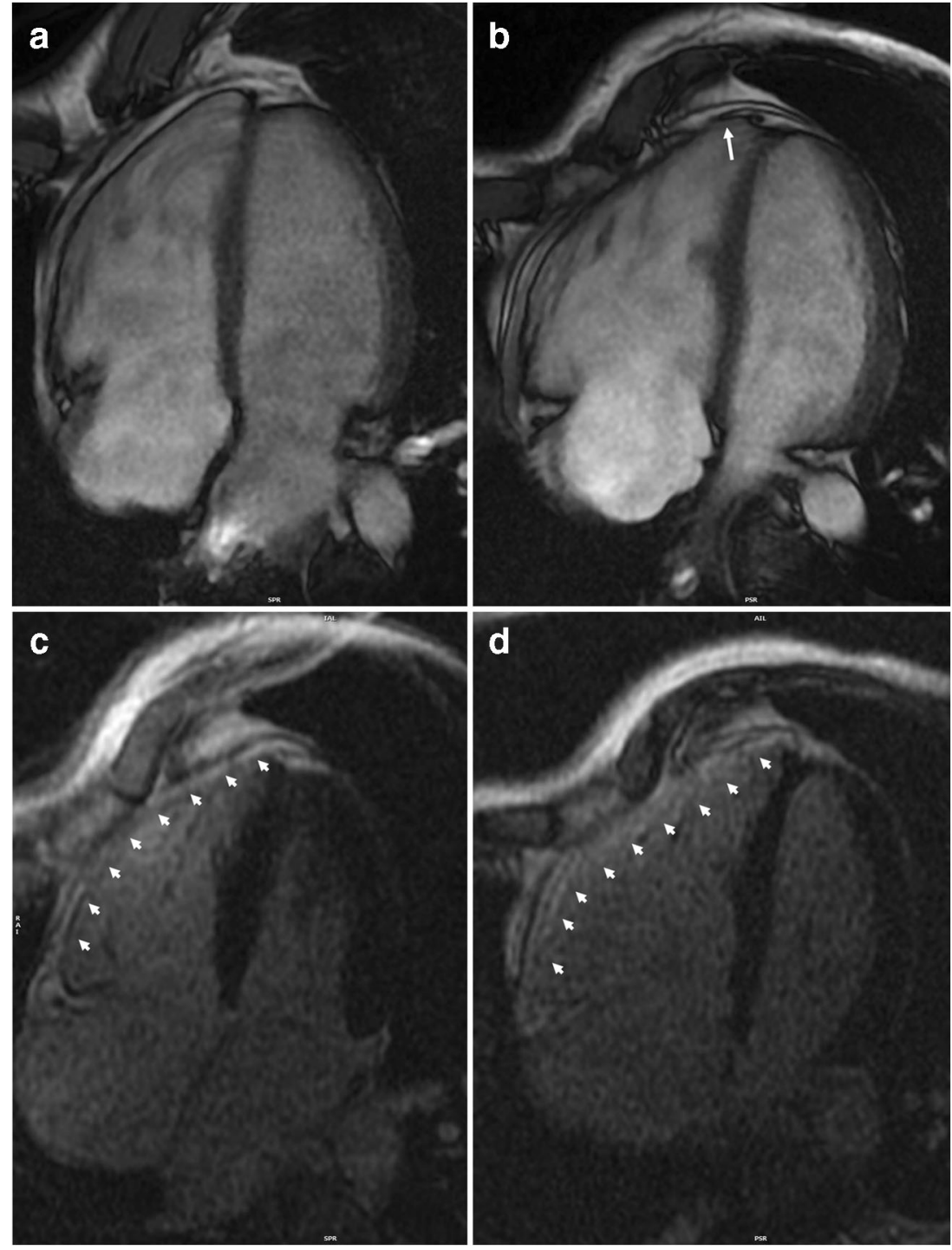

this subgroup, however, 2 of 3 patients that experienced appropriate ICD interventions during exercise were affected by ACM [41].

The association between continuing to practice high intensity exercise after ICD implantation and worse arrhythmic outcome was demonstrated by a study on 129 patients enrolled in the Johns Hopkins ACM registry, of whom $80 \%$ were athletes engaged in intense sports activity before the diagnosis (>936 METs*Hours yearly) [35]. More than half of patients (66/129) received appropriate ICD therapy during a median follow-up of 5.1 years. The chance of experiencing an appropriate intervention was directly related with the reduction of physical activity compared with baseline, and the correlation between exercise dose reduction and arrhythmic outcome was strengthen after correction for demographics, exercise dose before presentation, and established arrhythmic risk factors. The hazard ratio of 0.14 at multivariate analysis translated into an $86 \%$ lower risk of ICD therapy of those who reduced the exercise dose the most compared to those who reduced the least, independently from other variables. Of note, reducing the exercise "dose," which takes into account the intensity of the activity, demonstrated higher effect in decreasing arrhythmic risk than just maintaining the same intensity for a shorter duration.

Finally, it should be emphasized that the reasons for competitive sports restriction in young patients with a prophylactic ICD go beyond the increased arrhythmic risk. As discussed, intense exercise plays a role in disease progression by accelerating the process of myocyte death and fibro-fatty replacement, thus worsening ventricular dysfunction.

In conclusion, considering the above-discussed evidence, there is general agreement that the implant of an ICD should not be considered a justification for participation of patients with ACM in competitive sports or high-intensity noncompetitive physical activities, particularly in high-risk patients. On the other hand, compliance or not to exercise restriction 


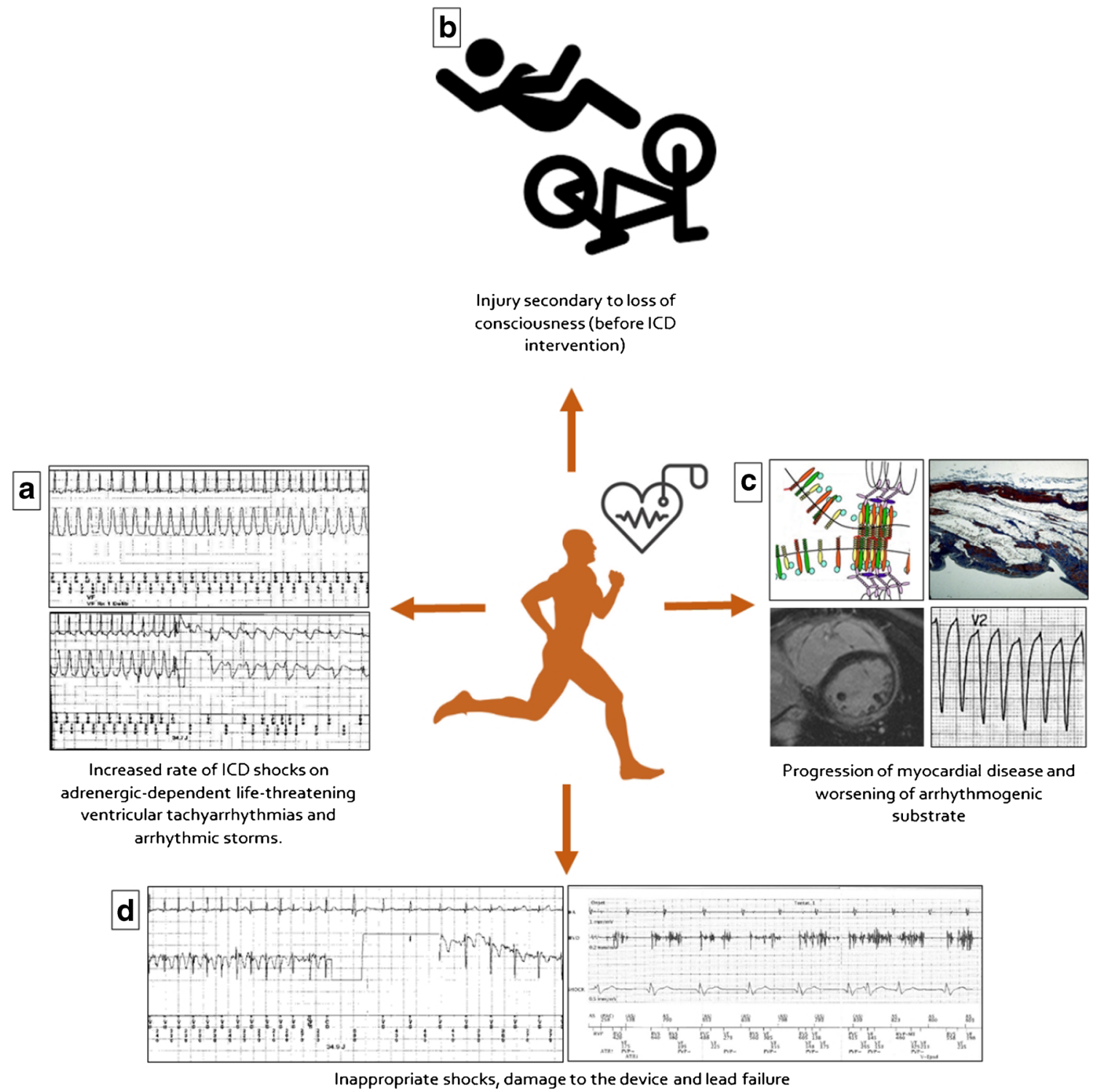

Fig. 4 Potential unfavorable effects of sports activity in patients/athletes with an ICD. Sports in ICD carriers are potentially associated with an increased risk of: adrenergic-dependent ventricular tachyarrhythmias (a); athlete's injury caused by loss of consciousness due to a syncopal tachyarrhythmia before the ICD intervention (b); development of phenotypic expression and accelerate disease progression of the

should be considered as an important factor in the decision to implant an ICD in intermediate-risk patients.

\section{Differentiating ACM and Athlete's Heart}

The long-running Italian experience with pre-participation screening demonstrated that early identification of affected individuals and restriction from competitive sports activity can substantially reduce the risk of SD $[8,42]$. The electrical and structural remodelling of the athlete's heart may sometimes require differential diagnosis with ACM. Although a underlying arrhythmogenic cardiomyopathy (c); inappropriate shocks caused by supraventricular tachycardia during sports activity (d, left) or by lead fracture with ventricular channel oversensing (d, right) (reproduced with permission from: Corrado D et al. Eur J Prev Cardiol. 2019 May;26(7):760-763. doi: 10.1177/2047487318805584. Epub 2018 Oct 18, with permission from Oxford University Press) [39]

detailed analysis of all elements useful for differentiating the two conditions goes beyond the scope of the review, some key points are:

1) ACM is an inherited disorder and family history of cardiomyopathies, and premature SD should be extended beyond first-degree family members. It is noteworthy that end-stage ACM can be confused with dilated cardiomyopathy [43].

2) Structural remodelling of the athlete's heart may cause $\mathrm{RV}$ dilation (mainly the main body rather than the outflow tract) that parallels left ventricular dilation (right/left 
ventricular ratio remains $<1$ ) and is never accompanied by regional wall motion abnormalities. Mild global dysfunction may be observed at rest in highly trained athletes, but exercise echocardiography demonstrates normalization of contractility [44-46].

3) At cardiac magnetic resonance, only the presence of lateenhancement at the insertion points between the right and left free wall and the septum (junctional late enhancement) can be considered normal in athletes [37].

4) VAs, at rest or during exercise, are observed in a minority of athletes versus the majority of ACM patients [47-50]. Arrhythmias at exercise testing were also observed in the majority of asymptomatic desmosomal gene-mutation carriers without structural changes at cardiac magnetic resonance suggesting that VAs may be the first manifestation of ACM [51]. Besides its diagnostic value, exercise testing appears particularly useful for evaluating the threshold of VAs onset when prescribing moderateintensity exercise in ACM patients.

5) Although multiple ECG abnormalities may be observed in ACM, T-wave inversion in the anterior leads V1-V4 is the most common and should always raise the suspicion of an

\section{ATHLETE'S HEART}
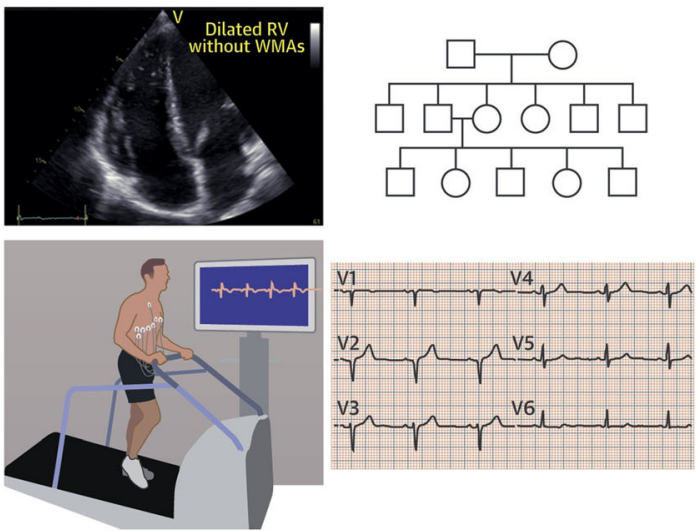

underlying disease. In the athlete, anterior T-wave inversion should be considered normal only before pubertal development ("juvenile pattern of repolarization") or in black individuals when preceded by J-point/ST-segment elevation (early repolarization variant typical of Afro-Caribbean athletes) [52].

6) The evaluation of an athlete should be multi-parametric: although no single test is diagnostic of ACM, the association of more than one abnormality at family history, resting, and exercise ECG and imaging increases the probability of a disease (Fig. 5).

\section{Competitive Sport, Leisure Time Physical Activity and ACM: Current Guidelines}

Table 2 summarizes the recommendations for competitive sports participation and leisure time physical activity according to recent guidelines and consensus documents. They all agree that patients with ACM should not engage in competitive sport, with the possible exception of skills disciplines, or high-intensity leisure time physical exercise. According to the

\begin{tabular}{|c|c|c|}
\hline Negative & Family history & Sudden death or ARVC \\
\hline Absent & ECG abnormalities & $\begin{array}{l}\text { QRS abnormalities, } \\
\text { T-wave Inversion }\end{array}$ \\
\hline Mainly main body & RV dilation & Mainly RVOT \\
\hline$<1$ & RV/LV Ratio & $>1$ \\
\hline Absent (or mild) & RV dysfunction & Present \\
\hline Absent & $\mathrm{RV}$ regional WMA & Present \\
\hline $\begin{array}{c}\text { Absent } \\
\text { (or only junctional) }\end{array}$ & $\begin{array}{l}\text { Late enhancement } \\
\text { at CMR }\end{array}$ & $\begin{array}{c}\mathrm{RV} \text { and/or LV LGE } \\
\text { with nonischemic distribution }\end{array}$ \\
\hline Absent & Ventricular arrhythmias & Present \\
\hline
\end{tabular}

Fig. 5 Differential diagnosis between arrhythmogenic cardiomyopathy and athlete's heart. The differential diagnosis between athlete's heart and arrhythmogenic right ventricular cardiomyopathy includes imaging features and comprehensive clinical approaches including ECG, ambulatory ECG monitoring, stress testing, and evaluation of family members. CMR, cardiac magnetic resonance; ECG, electrocardiography; LGE, late gadolinium enhancement; LV, left ventricular; RV, right ventricular; RVOT, right ventricular outflow tract; WMA, wall motion abnormality (reproduced with permission from: D'Ascenzi $F$ et al. JACC Cardiovasc Imaging. 2018 Sep;11(9):1327-1339. doi: 10.1016/j.jcmg.2018.04.031, with permission from Elsevier) [53] 
Table 2 Summary of recommendations for competitive sports participation and leisure time physical activity according to recent guidelines and consensus documents

\begin{tabular}{|c|c|c|}
\hline Document & Recommendations for competitive sports & $\begin{array}{l}\text { Recommendations for leisure } \\
\text { time physical activity }\end{array}$ \\
\hline $\begin{array}{l}2015 \text { AHA/ACC competitive sports } \\
\text { eligibility guidelines [52] }\end{array}$ & $\begin{array}{l}\text { - No competitive sports (with the possible } \\
\text { exception of skill sports) for possible, } \\
\text { borderline or definite ACM } \\
\text { - ICD placement for permitting participation in } \\
\text { high-intensity sport not recommended }\end{array}$ & Not addressed \\
\hline $\begin{array}{l}2015 \text { International Task Force } \\
\text { Consensus Statement on the } \\
\text { Treatment of ARVC [54] }\end{array}$ & $\begin{array}{l}\text { - No competitive sports in patients with definite ACM } \\
\text { - Restriction from competitive sports activity may be considered in } \\
\text { ACM family members with a negative phenotype, either healthy } \\
\text { gene carriers or with unknown genotype }\end{array}$ & - Low-intensity exercise may be allowed \\
\hline $\begin{array}{l}2019 \text { EAPC recommendations for } \\
\text { participation in competitive and } \\
\text { leisure time sport in athletes with } \\
\text { cardiomyopathies [55] }\end{array}$ & $\begin{array}{l}\text { - No competitive sports in patients with definite or borderline ACM } \\
\text { and gene positive/phenotype negative patients }\end{array}$ & - Low-intensity exercise recommended \\
\hline 2019 HRS guidelines on ACM [56] & $\begin{array}{l}\text { - No competitive sports in ACM patients and gene } \\
\text { positive/phenotype negative patients }\end{array}$ & $\begin{array}{l}\text { - Frequent high-intensity endurance exercise not } \\
\text { advised in ACM patients and gene } \\
\text { positive/phenotype negative patients } \\
\text { - Preference for low-intensity activities }\end{array}$ \\
\hline $\begin{array}{l}2020 \text { ESC guidelines sports cardiology } \\
\text { and exercise in patients with } \\
\text { cardiovascular disease [25] }\end{array}$ & $\begin{array}{l}\text { - No competitive sports of any type in ACM patients and gene } \\
\text { positive/phenotype negative patients }\end{array}$ & $\begin{array}{l}\text { - Low-intensity exercise, } 150 \mathrm{~min} / \mathrm{week} \text {, for all } \\
\text { - Moderate intensity exercise only in low-risk } \\
\text { patients* } \\
\text { - High intensity not advised }\end{array}$ \\
\hline
\end{tabular}

$A C M$ arrhythmogenic cardiomyopathy, ACC American college of cardiology, AHA American heart association, EAPC European association of preventive cardiology, ESC European society of cardiology, ICD implantable cardioverter defibrillator, $H R S$ heart rhythm society

*Low risk $=$ no history of cardiac arrest or ventricular tachycardia, low arrhythmic burden ( $<500 \mathrm{PVBs} /$ day, no exercise-induced arrhythmias $)$, minimal structural abnormalities

2015 American Heart Association/American College of Cardiology guidelines, healthy gene carriers are not precluded from participation in competitive sports [54]. Conversely, more recent documents are more restrictive because of emerging evidence that regular exercise training and competitive sports can play a role in triggering cellular mechanisms leading to the development and progression of the disease phenotype in the presence of a predisposing gene abnormality [25, 55-57].

\section{Conclusions}

There is compelling evidence from both animal and human studies that exercise is an important modulating factor in ACM that may favor disease penetrance in genotype positive/phenotype negative patients, worsen ventricular dysfunction, and trigger arrhythmias. For these reasons, there is unanimous consensus that ACM patients should be advised against participation in competitive sports (with the possible exception of skill disciplines at low-cardiovascular demands in selected cases) and high-intensity leisure time physical activity. On the other hand, ACM patients, particularly young with a mild disease, should not be deprived from the many health benefits of low-to-moderate intensity physical activity. In ACM, exercise is a medicine with a narrow therapeutic range and should be prescribed by experienced physicians on a case-by-case basis.
Funding Open access funding provided by Università degli Studi di Padova within the CRUI-CARE Agreement. Registry for CardioCerebro-Vascular Pathology, Veneto Region, Venice, Italy; Ministry of Health grant RF_I $\backslash 2014$ I $\backslash 00000394$; University Research grants CPDA144300 and BIRD162733, Padua, Italy; PRIN Ministry of Education, University and Research 2015ZLNETW_001, Rome, Italy; and the CARIPARO Foundation, Padua, Italy.

\section{Declarations}

Conflict of Interest The authors declare that they have no conflict of interest.

Human and Animal Rights and Informed Consent This article does not contain any studies with human or animal subjects performed by any of the authors.

Open Access This article is licensed under a Creative Commons Attribution 4.0 International License, which permits use, sharing, adaptation, distribution and reproduction in any medium or format, as long as you give appropriate credit to the original author(s) and the source, provide a link to the Creative Commons licence, and indicate if changes were made. The images or other third party material in this article are included in the article's Creative Commons licence, unless indicated otherwise in a credit line to the material. If material is not included in the article's Creative Commons licence and your intended use is not permitted by statutory regulation or exceeds the permitted use, you will need to obtain permission directly from the copyright holder. To view a copy of this licence, visit http://creativecommons.org/licenses/by/4.0/. 


\section{References}

Papers of particular interest, published recently, have been highlighted as:

- Of importance

•- Of major importance

1. Corrado D, Link MS, Calkins H. Arrhythmogenic right ventricular cardiomyopathy. N Engl J Med. 2017;376:61-72.

2. Zorzi A, Rigato I, Bauce B, Pilichou K, Basso C, Thiene G, et al. Arrhythmogenic right ventricular cardiomyopathy: risk stratification and indications for defibrillator therapy. Curr Cardiol Rep. 2016;18:57.

3. Marra MP, Leoni L, Bauce B, Corbetti F, Zorzi A, Migliore F, et al. Imaging study of ventricular scar in arrhythmogenic right ventricular cardiomyopathy comparison of 3D standard electroanatomical voltage mapping and contrast-enhanced cardiac magnetic resonance. Circ Arrhythm Electrophysiol. 2012;5:91-100.

4. Corrado D, Perazzolo Marra M, Zorzi A, Beffagna G, Cipriani A, De Lazzari M, et al. Diagnosis of arrhythmogenic cardiomyopathy: the Padua criteria. Int J Cardiol. 2020;319:106-14 The proposed modification of the diagnostic criteria for arrhythmogenic cardiomyopathy was developed to take into consideration the emerging role of cardiac magnetic resonance and to increase the sensitivity for left-sided variants.

5. Bariani R, Cipriani A, Rizzo S, Celeghin R, Marinas M, Giorgi B, et al. "Hot phase" clinical presentation in arrhythmogenic cardiomyopathy. Europace. 2021; In press. https://doi.org/10.1093/ europace/euaa343.

6. Thiene G, Nava A, Corrado D, Rossi L, Pennelli N. Right ventricular cardiomyopathy and sudden death in young people. N Engl J Med. 1988;318:129-33.

7. Corrado D, Basso C, Rizzoli G, Schiavon M, Thiene G. Does sports activity enhance the risk of sudden death in adolescents and young adults? J Am Coll Cardiol. 2003;42:1959-63.

8. Corrado D, Basso C, Pavei A, Michieli P, Schiavon MTG. Trends in sudden cardiovascular death in young competitive athletes. JAMA. 2006;296:1593-601.

9. Finocchiaro G, Papadakis M, Robertus JL, Dhutia H, Steriotis AK, Tome M, et al. Etiology of sudden death in sports insights from a United Kingdom Regional Registry. J Am Coll Cardiol. 2016;67: 2108-15.

10. Corrado D, Zorzi A. Sudden death in athletes. Int J Cardiol. 2017;237:67-70.

11. Kirchhof P, Fabritz L, Zwiener M, Witt H, Schäfers M, Zellerhoff $\mathrm{S}$, et al. Age- and training-dependent development of arrhythmogenic right ventricular cardiomyopathy in heterozygous plakoglobin-deficient mice. Circulation. 2006;114:1799-806.

12. Fabritz L, Hoogendijk MG, Scicluna BP, Van Amersfoorth SCM, Fortmueller L, Wolf S, et al. Load-reducing therapy prevents development of arrhythmogenic right ventricular cardiomyopathy in plakoglobin-deficient mice. J Am Coll Cardiol. 2011;57:740-50.

13. Cruz FM, Sanz-Rosa D, Roche-Molina M, García-Prieto J, GarcíaRuiz JM, Pizarro G, et al. Exercise triggers ARVC phenotype in mice expressing a disease-causing mutated version of human plakophilin-2. J Am Coll Cardiol. 2015;65:1438-50.

14. Moncayo-Arlandi J, Guasch E, de la Garza MS, Casado M, Garcia NA, Mont L, et al. Molecular disturbance underlies to arrhythmogenic cardiomyopathy induced by transgene content, age and exercise in a truncated PKP2 mouse model. Hum Mol Genet. 2016;25: 3676-88.

15. Cheedipudi SM, Hu J, Fan S, Yuan P, Karmouch J, Czernuszewicz $\mathrm{G}$, et al. Exercise restores dysregulated gene expression in a mouse model of arrhythmogenic cardiomyopathy. Cardiovasc Res. 2020;116:1199-213.

16.• James CA, Bhonsale A, Tichnell C, Murray B, Russell SD, Tandri $\mathrm{H}$, et al. Exercise increases age-related penetrance and arrhythmic risk in arrhythmogenic right ventricular dysplasia/cardiomyopathyassociated desmosomal mutation carriers. J Am Coll Cardiol. 2013;62(14):1290-97. The study demonstrated for the first time in human subjects that a history of intense exercise activity was reported more often in desmosomal gene mutation carriers who developed arrhythmogenic cardiomyopathy and in patients with arrhythmogenic cardiomyopathy who experienced major ventricular arrhythmias.

17. Sawant ACM, Bhonsale A, te Riele ASJM, Tichnell C, Murray B, Russell SD, et al. Exercise has a disproportionate role in the pathogenesis of arrhythmogenic right ventricular dysplasia/ cardiomyopathy in patients without desmosomal mutations. J Am Heart Assoc. 2014;3:e001471.

18. Saberniak J, Hasselberg NE, Borgquist R, Platonov PG, Sarvari SI, Smith HJ, et al. Vigorous physical activity impairs myocardial function in patients with arrhythmogenic right ventricular cardiomyopathy and in mutation positive family members. Eur J Heart Fail. 2014;16:1337-44.

19. Ruwald ACM, Marcus F, Estes NAM, Link M, McNitt S, Polonsky $\mathrm{B}$, et al. Association of competitive and recreational sport participation with cardiac events in patients with arrhythmogenic right ventricular cardiomyopathy: results from the North American multidisciplinary study of arrhythmogenic right ventricular cardiomyopath. Eur Heart J. 2015;36:1735-43.

20. Lie ØH, Dejgaard LA, Saberniak J, Rootwelt C, Stokke MK, Edvardsen T, et al. Harmful effects of exercise intensity and exercise duration in patients with arrhythmogenic cardiomyopathy. JACC Clin Electrophysiol. 2018;4:744-53.

21. Ruiz Salas A, Barrera Cordero A, Navarro-Arce I, Jiménez Navarro M, García Pinilla JM, Cabrera Bueno F, et al. Impact of dynamic physical exercise on high-risk definite arrhythmogenic right ventricular cardiomyopathy. J Cardiovasc Electrophysiol. 2018;29: 1523-9.

22. Müssigbrodt A, Czimbalmos C, Stauber A, Bertagnolli L, Bode K, Dagres N, et al. Effect of exercise on outcome after ventricular tachycardia ablation in arrhythmogenic right ventricular dysplasia/ cardiomyopathy. Int J Sports Med. 2019;40:657-62.

23. Paulin FL, Hodgkinson KA, MacLaughlan S, Stuckless SN, Templeton C, Shah S, et al. Exercise and arrhythmic risk in TMEM43 p.S358L arrhythmogenic right ventricular cardiomyopathy. Heart Rhythm. 2020;17:1159-66.

24. Leischik R, Dworrak B, Strauss M, Horlitz M, Pareja-Galeano H. de la Guía-Galipienso F, et al. Exercise-induced right ventricular injury or arrhythmogenic cardiomyopathy (ACM): the bright side and the dark side of the moon. Prog Cardiovasc Dis. 2020;63:671-81.

25. Pelliccia A, Sharma S, Gati S, Bäck M, Börjesson M, Caselli S, et al. 2020 ESC guidelines on sports cardiology and exercise in patients with cardiovascular disease. Eur Heart J. 2020; in press. https://doi.org/10.1093/eurheartj/ehaa605.

26. Maron BJ, Haas TS, Ahluwalia A, Murphy CJ, Garberich RF. Demographics and epidemiology of sudden deaths in young competitive athletes: from the United States National Registry. Am J Med. 2016;129:1170-7.

27. De Lazzari M, Zorzi A, Cipriani A, Susana A, Mastella G, Rizzo A, et al. Relationship between electrocardiographic findings and cardiac magnetic resonance phenotypes in arrhythmogenic cardiomyopathy. J Am Heart Assoc. 2018;7:e009855.

28. Sen-Chowdhry S, Syrris P, Prasad SK, Hughes SE, Merrifield R, Ward D, et al. Left-dominant arrhythmogenic cardiomyopathy. An under-recognized clinical entity. J Am Coll Cardiol. 2008;52:217587. 
29. di Gioia CRT, Giordano C, Cerbelli B, Pisano A, Perli E, De Dominicis E, et al. Nonischemic left ventricular scar and cardiac sudden death in the young. Hum Pathol. 2016;58:78-89.

30. Zorzi A, Vessella T, De Lazzari M, Cipriani A, Menegon V, Sarto $\mathrm{G}$, et al. Screening young athletes for diseases at risk of sudden cardiac death: role of stress testing for ventricular arrhythmias. Eur J Prev Cardiol. 2020;27:311-20.

31. Cipriani A, Zorzi A, Sarto P, Donini M, Rigato I, Bariani R, et al. Predictive value of exercise testing in athletes with ventricular ectopy evaluated by cardiac magnetic resonance. Heart Rhythm. 2019;16:239-48.

32. Corrado D, Zorzi A. Arrhythmogenic right ventricular cardiomyopathy and sports activity. Eur Heart J. 2015;36:1708-10.

33. Heidbüchel H, Hoogsteen J, Fagard R, Vanhees L, Ector H, Willems R, et al. High prevalence of right ventricular involvement in endurance athletes with ventricular arrhythmias: role of an electrophysiologic study in risk stratification. Eur Heart J. 2003;24: 1473-80.

34. La Gerche A, Robberecht C, Kuiperi C, Nuyens D, Willems R, De Ravel T, et al. Lower than expected desmosomal gene mutation prevalence in endurance athletes with complex ventricular arrhythmias of right ventricular origin. Heart. 2010;96:1268-74.

35. Wang W, Orgeron G, Tichnell C, Murray B, Crosson J, Monfredi $\mathrm{O}$, et al. Impact of exercise restriction on arrhythmic risk among patients with arrhythmogenic right ventricular cardiomyopathy. J Am Heart Assoc. 2018;7:e008843.

36. Venlet J, Piers SRD, Jongbloed JDH, Androulakis AFA, Naruse Y, den Uijl DW, et al. Isolated subepicardial right ventricular outflow tract scar in athletes with ventricular tachycardia. J Am Coll Cardiol. 2017;69:497-507.

37. Zorzi A, Marra MP, Rigato I, De Lazzari M, Susana A, Niero A, et al. Nonischemic left ventricular scar as a substrate of lifethreatening ventricular arrhythmias and sudden cardiac death in competitive athletes. Circ Arrhythm Electrophysiol. 2016; $004229: 9$

38. Corrado D, Basso C, Leoni L, Tokajuk B, Bauce B, Frigo G, et al. Three-dimensional electroanatomic voltage mapping increases accuracy of diagnosing arrhythmogenic right ventricular cardiomyopathy/dysplasia. Circulation. 2005;111:3042-50.

39. Corrado D, Migliore F, Zorzi A. Sport activity in patients with implantable defibrillator: playing with death? Eur J Prev Cardiol. 2019;26:760-3.

40. Saarel EV, Law I, Berul CI, Ackerman MJ, Kanter RJ, Sanatani S, et al. Safety of sports for young patients with implantable cardioverter-defibrillators. Circ Arrhythm Electrophysiol. 2018;11:e06305 The registry included patients with heart diseases who received an implantable cardioverter defibrillator and continued to play sports; it demonstrated that arrhythmogenic cardiomyopathy was an independent predictor for appropriate ICD intervention.

41. Heidbuchel H, Willems R, Jordaens L, Olshansky B, Carre F, Lozano IF, et al. Intensive recreational athletes in the prospective multinational ICD Sports Safety Registry: results from the European cohort. Eur J Prev Cardiol. 2019;26:764-75.

42. Vessella T, Zorzi A, Merlo L, Pegoraro C, Giorgiano F, Trevisanato $\mathrm{M}$, et al. The Italian preparticipation evaluation programme: diagnostic yield, rate of disqualification and cost analysis. Br J Sports Med. 2020;54:231-7.

43. Cipriani A, Bauce B, De Lazzari M, Rigato I, Bariani R, Meneghin $\mathrm{S}$, et al. Arrhythmogenic right ventricular cardiomyopathy: characterization of left ventricular phenotype and differential diagnosis with dilated cardiomyopathy. J Am Heart Assoc. 2020;9:e014628.
44. D’Ascenzi F, Pelliccia A, Solari M, Piu P, Loiacono F, Anselmi F, et al. Normative reference values of right heart in competitive athletes: a systematic review and meta-analysis. J Am Soc Echocardiogr. 2017;30:845-58.

45. D'Ascenzi F, Anselmi F, Piu P, Fiorentini C, Carbone SF, Volterrani L, et al. Cardiac magnetic resonance normal reference values of biventricular size and function in male athlete's heart. JACC Cardiovasc Imaging. 2019;12:1755-65.

46. D'Ascenzi F, Pisicchio C, Caselli S, Di Paolo FM, Spataro A, Pelliccia A. RV Remodeling in Olympic athletes. JACC Cardiovasc Imaging. 2017;10:385-93.

47. Zorzi A, De Lazzari M, Mastella G, Niero A, Trovato D, Cipriani A, et al. Ventricular arrhythmias in young competitive athletes: prevalence, determinants, and underlying substrate. J Am Heart Assoc. 2018;7:e009171.

48. Zorzi A, Mastella G, Cipriani A, Berton G, Del Monte A, Gusella $\mathrm{B}$, et al. Burden of ventricular arrhythmias at 12-lead 24-hour ambulatory ECG monitoring in middle-aged endurance athletes versus sedentary controls. Eur J Prev Cardiol. 2018;25:2003-11.

49. D'Ascenzi F, Zorzi A, Alvino F, Bonifazi M, Corrado D, Mondillo $\mathrm{S}$. The prevalence and clinical significance of premature ventricular beats in the athlete. Scand J Med Sci Sports. 2017;27:140-51.

50. Corrado D, Drezner JA, D'Ascenzi F, Zorzi A. How to evaluate premature ventricular beats in the athlete: critical review and proposal of a diagnostic algorithm. Br J Sports Med. 2020;54:1142-8.

51. Perrin MJ, Angaran P, Laksman Z, Zhang H, Porepa LF, Rutberg J, et al. Exercise testing in asymptomatic gene carriers exposes a latent electrical substrate of arrhythmogenic right ventricular cardiomyopathy. J Am Coll Cardiol. 2013;62:1772-9.

52. Zorzi A, Vio R, Bettella N, Corrado D. Criteria for interpretation of the athlete's ECG: a critical appraisal. Pacing Clin Electrophysiol. 2020;43:882-90.

53. D'Ascenzi F, Solari M, Corrado D, Zorzi A, Mondillo S. Diagnostic differentiation between arrhythmogenic cardiomyopathy and athlete's heart by using imaging. JACC Cardiovasc Imaging. 2018;11:1327-39.

54. Maron BJ, Udelson JE, Bonow RO, Nishimura RA, Ackerman MJ, Estes NAM, et al. Eligibility and disqualification recommendations for competitive athletes with cardiovascular abnormalities: Task Force 3: Hypertrophic Cardiomyopathy, Arrhythmogenic Right Ventricular Cardiomyopathy and Other Cardiomyopathies, and Myocarditis: a scientific statement from the American Heart Association and American College of Cardiology. J Am Coll Cardiol. 2015;132:e273-80.

55. Corrado D, Wichter T, Link MS, Hauer R, Marchlinski F, Anastasakis A, et al. Treatment of arrhythmogenic right ventricular cardiomyopathy/dysplasia: an international task force consensus statement. Eur Heart J. 2015;36:3227-37.

56. Pelliccia A, Solberg EE, Papadakis M, Adami PE, Biffi A, Caselli $\mathrm{S}$, et al. Recommendations for participation in competitive and leisure time sport in athletes with cardiomyopathies, myocarditis, and pericarditis: position statement of the Sport Cardiology Section of the European Association of Preventive Cardiology (EAPC). Eur Heart J. 2019;40:19-33.

57. Towbin JA, McKenna WJ, Abrams DJ, Ackerman MJ, Calkins H, Darrieux FCC, et al. HRS expert consensus statement on evaluation, risk stratification, and management of arrhythmogenic cardiomyopathy. Hear Rhythm. 2019. 2019;16:e301-72.

Publisher's Note Springer Nature remains neutral with regard to jurisdictional claims in published maps and institutional affiliations. 